\title{
HUME E PEIRCE ACERCA DO CETICISMO CARTESIANO
}

Sara Albieri ${ }^{1}$

RESUMO Hume e Peirce criticam o ceticismo cartesiano baseados em concepções análogas de dúvida e crença enquanto constitutivas do processo de conhecimento. Este artigo visa apresentar a teoria do conhecimento desses autores, baseada na crença, enquanto alternativa ao fundacionismo racionalista de Descartes.

Palavras-chave: Hume, Peirce, Descastes, ceticismo

ABSTRACT Hume and Peirce criticize Descartes'skepticism based on similar conceptions of doubt and belief as constituent parts of the cognitive process. This paper aims at throwing some light on their theory knowledge based on belief as an alternative to Descartes' rationalist foundationalism.

Na Seção XII da Investigação sobre o Entendimento Humano David Hume discute o ceticismo filosófico. Ele começa por objetar ao ceticismo praticado por Descartes, aquele "anterior a todo estudo e filosofia", que consistiria num "preservativo soberano contra o erro e o juízo precipitado".Contra Descartes, ele expõe seus argumentos num breve parágrafo:

"Esse ceticismo recomenda uma dúvida universal não só das opiniões e princípios que até então perfilhávamos, como também de nossas próprias faculdades. Dizem os nossos filósofos que devemos assegurar-nos da veracidade dessas opiniões e princí-

Universidade Federal de Santa Catarina. Artigo recebido em setembro e aprovado em outubro.

KRITERION, Belo Horizonte, $n^{0}$ 108, Dez/2003, p.244-252 
pios por uma cadeia de raciocínio deduzida de algum princípio original que absolutamente não possa ser falaz ou ilusório. Mas, ou não existe nenhum princípio original dessa sorte que tenha prerrogativa sobre os outros princípios convincentes e evidentes por si mesmos, ou, se os houvesse, não poderíamos avançar um passo além deles a não ser pelo uso dessas mesmas faculdades de que nos aconselham a suspeitar. A dúvida cartesiana, portanto, se pudesse ser alcançada por alguma criatura humana (o que evidentemente não pode), seria de todo incurável; e nenhum raciocínio nos poderia conduzir jamais a um estado de segurança e convicção a respeito de qualquer assunto". (EHU, xii, § 116).

Penso que o alcance do segundo desses argumentos é mais evidente do que o do primeiro. Basta lembrarmos da Meditação Primeira. Descartes começa por atacar a fé que depositamos em nossos sentidos. Em seguida põe em cheque o mundo sensóreo através do argumento do sonho. Finalmente, a hipótese do Gênio Maligno atinge a confiabilidade de nossas certezas racionais. Ou seja, como diz Hume, não só lança dúvida sobre nossas opiniões e princípios, como suspeita de nossas faculdades: aquilo que à razão parece evidente pode apenas ser o resultado da intervenção do Gênio sobre nossa capacidade de raciocinar.

O caminho cartesiano chega, na Meditação seguinte, ao "eu penso, eu existo" como uma primeira certeza. Ela retira sua evidência de uma posição negativa: mesmo que o Gênio me engane em tudo, é preciso que exista esse algo que é objeto do engano. Tenho certeza de que sou, ainda que apenas enquanto fantoche das estripulias daquele ente. Mas, ainda que se aceite a clareza e evidência dessa primeira certeza, é igualmente claro que tal princípio não tem o poder de iluminar a passagem para nenhum outro. Exceto pelo fato de o enganado ser $e u$, o Gênio Maligno continua a obscurecer a evidência de tudo o mais. Ele torna a luz natural ineficaz para clarear qualquer verdade de razão.

Como sabemos, a estratégia de Descartes para restaurar a confiabilidade da razão e neutralizar a ação do Gênio Maligno é provar a existência de Deus Misericordioso. Ele a prova, em primeiro lugar, pelo exame das diferentes idéias presentes em seu pensamento, reconhecendo dentre elas a idéia de um Ser infinitamente perfeito, e argumentando que somente tal idéia tem valor objetivo, isto é, não poderia ter outra origem senão n'Ele. (Meditação Terceira, §§15-19). E já nesse primeiro passo para além do cogito incorre numa dificuldade. Quando conclui que não pode conceber o infinito sendo seu eu finito, ou a perfeição sendo imperfeito, sendo, portanto, a causa de tais idéias exterior a seu espírito, recorre à regra da proporcionalidade entre causa e efeito: não pode haver mais realidade no efeito que na causa; não pode o finito eu causar a idéia do infinito Deus. 


\begin{abstract}
"Agora, é coisa manifesta pela luz natural que deve haver ao menos tanta realidade na causa eficiente e total quanto no seu efeito: pois de onde é que o efeito pode tirar sua realidade senão de sua causa? E como poderia esta causa lha comunicar se não a tivesse em si mesma? Daí decorre não somente que o nada não poderia produzir coisa alguma, mas também que o que é mais perfeito, isto é, o que contém em si mais realidade, não pode ser uma decorrência e uma dependência do menos perfeito." (Meditação Terceira, §§16-17)
\end{abstract}

Ora, tal regra tem o estatuto de uma verdade de razão, daquelas que obedecem ao critério cartesiano de clareza e distinção. Contudo poderia bem ter sido assim "clareada" pelo Gênio Maligno. Configura-se assim uma argumentação circular, já apontada ao próprio Descartes em seu tempo por alguns objetores, e conhecida entre os intérpretes posteriores de sua obra como o "círculo cartesiano":

"se é preciso que se confirme a existência de um Deus veraz para que eu tenha confiança nas percepções claras e distintas de meu intelecto, então como posso, sem incorrer em circularidade, basear-me na percepções intelectuais que foram, no princípio, necessárias à construção da prova da existência de Deus?"

(Cottingham, 1995, p.34)

O critério de clareza e distinção, tão necessário a Descartes para escapar ao ceticismo e reconstruir uma a uma as certezas postas sob suspeita pela dúvida metódica, para ser aplicado, necessitaria já da confiabilidade da razão. É necessário que a evidência racional possa clarear não só o ponto inicial ou final da investigação e da busca pela certeza, como possa acompanhar os seus pontos de apoio. Mas, se aceitamos a hipótese do Gênio Maligno, não há como confiar em tal evidência. A saída do cogito pela via da clareza e distinção, como a que Descartes encontra, parece então, como diz Hume, contar com as mesmas faculdades que estão sob suspeita.

A propósito dessa dificuldade, Descartes assim respondeu a seus objetores :

"onde afirmei que nada podemos saber de certo, se não conhecermos primeiramente que Deus existe, afirmei, em termos expressos, que falava apenas da ciência dessas conclusões, cuja lembrança nos pode retornar ao espírito, quando não mais pensamos nas razões de onde as tiramos." (Respostas às Segundas Objeções, p.218)

Deus preserva então a certeza dos passos que conduzem às verdades demonstradas. Se emprego uma fórmula matemática sem a cada vez recordar e reconstituir a demonstração da qual foi derivada, tais passos raciocinados não obstante continuam claros e disponíveis na razão divina, garantindo a verdade de meus procedimentos "abreviados". Mas esse Seu papel não exclui que pos- 
samos conhecer com clareza primeiros princípios e axiomas mesmo antes de provar a existência d'Ele; e o cogito é dessa ordem, conhecido "por simples inspeção do espírito. (Segundas Respostas, p.219) Ou seja, o Gênio não teria poder para alterar o poder da razão enquanto faculdade; apenas tornaria duvidosas as conclusões de suas operações.

Mas então a ação do Gênio Maligno sobre a razão é mais limitada do que Descartes de início parece alegar, permitindo que permaneça intacta o que seus intérpretes hoje chamam de "regra da verdade" (Cottingham,1995, p.37): "Tudo aquilo que percebo como claro e distinto é verdadeiro", com ou sem Gênio. E a partir disso fica claro o primeiro argumento de Hume. Segundo ele, o cogito enquanto primeiro princípio não poderia reivindicar maior evidência que outros princípios igualmente claros e auto-evidentes. O que está de acordo com a dita "regra": a razão enquanto intuição intelectual pode reconhecer clara e distintamente outros princípios que não o cogito, uma vez que não envolvem prova ou demonstração.

"Engane-me quem puder, ainda assim jamais poderá fazer que eu nada seja enquanto eu pensar que sou algo; ou que algum dia seja verdade que eu não tenha jamais existido, sendo verdade agora que eu existo; ou então que dois e três juntos façam mais ou menos do que cinco, ou coisas semelhantes, que vejo claramente não poderem ser de outra maneira senão como as concebo. (Meditação Terceira, §4; grifo meu)

Descartes quer nos convencer que o cogito é o único princípio que resiste à dúvida apenas porque, dentre os possíveis princípios percebidos clara e distintamente, é aquele que permite à argumentação avançar em direção à prova da existência de Deus e à restauração das demais certezas. Toda a argumentação de Descartes parece ter o sentido de apoiar e justificar essa conclusão. É igualmente clara, porém, a conveniência dessa escolha, confirmando a primeira objeção de Hume, à luz da qual a resposta cartesiana ao ceticismo não se afigura tão radical.

De resto, a objeção de Hume é coerente com a tradição cética. Sexto Empírico, nas Hipotiposes Pirronianas, recorda os cinco modos de Agripa contra a razão. Um deles aponta para a dificuldade de estabelecer um primeiro princípio ou ponto de partida, para o qual sempre é possível se exigir uma prova, e depois a prova da prova, ao infinito. Se, por outro lado, alguém resolve dar um basta à investigação e assumir um princípio sem prova, declarando sua autoevidência (como seria o caso do cogito), este recairia no modo da hipótese, perdendo em força fundadora e sugerindo seu caráter arbitrário.(Hipotiposes, I,§§164-169) Ao alegar que a primeira certeza cartesiana não teria prerrogativa sobre qualquer outra de mesmo estatuto, Hume aponta para o arbitrário do cogito, para seu caráter de dogma. 
A critica humeana ao ceticismo cartesiano é contundente, mas breve. Hume não explicita os modos pelos quais sua teoria da crença, o lado construtivo de sua teoria do conhecimento, poderia constituir-se numa alternativa ao fundacionismo cartesiano. A tarefa de atar esses nós ele deixa a leitores como C.S.Peirce, um filósofo cuja herança humeana ainda está por ser adequadamente esclarecida.

Em três artigos particularmente, A Fixação da Crença, Como tornar nossas Idéias Claras e Algumas Conseqüências de Quatro Incapacidades, Peirce discute, entre outros temas, a questão dos princípios, dos pontos de partida $a$ priori nos sistemas filosóficos. Peirce nos diz que, se examinarmos a história do pensamento metafísico em filosofia, veremos que os sistemas em geral não se constroem apoiados em "fatos observados", mas sobre proposições de fundamento que parecem "agradáveis à razão". Peirce enfatiza os compromissos dessa escolha: "isto não se refere àquilo que concorda com a experiência, mas àquilo em que nos sentimos inclinados a acreditar”.(FB,1958, p.106).

Naturalmente o pensador metafísico não reconhece tal crítica. Ele apóia a escolha dos princípios de seu sistema no que alega serem argumentos cabais. É o caso de Descartes - e do critério de clareza e distinção, que fez escola no pensamento lógico. Peirce comenta o desdobramento do critério cartesiano em duas distinções: entre concepções claras e obscuras, e entre distintas e confusas. Clareza sendo, no dizer de Peirce, a característica daquelas idéias que reconhecemos; parece pouco, e por isso os lógicos acrescentam que é preciso adicionar-lhe a distinção.

"Uma idéia distinta é definida como aquela que nada contem que não seja claro. Isto é linguagem técnica; por conteúdos de uma idéia os lógicos entendem o que quer que esteja contido em sua definição. De modo que uma idéia é apreendida distintamente, de acordo com eles, quando podemos fornecer uma definição precisa dela em termos abstratos".(HM,1958, p.115)

Peirce não considera essa retomada pela lógica dos conceitos cartesianos como um aprimoramento. Ao contrário, diz tratar-se uma questão de há muito extinta com a filosofia que a gerou, recomendando que a lógica ficasse atenta para as contribuições do pensamento de seu tempo. Quando Descartes iniciou a reconstrução da filosofia a partir do que Peirce denomina "autoconsciência", sua primeira condição para distinguir as idéias verdadeiras daquelas falsas é que aquelas deveriam ser claras. Mas a Descartes não ocorreu distinguir entre uma idéia que parece clara e uma que de fato o é. Isso porque a introspecção só permite distinguir o que é agradável à própria razão, e que pode ser diverso do que agrada à razão de outro. 
É claro que Descartes não pretende que o valor do cogito, da primeira certeza, seja o de uma evidência obtida por introspecção, portanto psicológica. Gerard Lebrun assim observa em nota às segundas objeções: "Os teólogos interpretaram a certeza como um estado psicológico entre outros. Para Descartes, o termo é mais determinado: pensamento de um objeto tal que, devido ao próprio fato de eu pensá-lo, não posso duvidar de sua verdade." (Segundas Objeções, p.223n31) Mas Peirce não se deixa convencer e estende a Descartes o essencial de sua própria concepção de crença: "Aceitar proposições que nos parecem perfeitamente evidentes é algo que, quer seja lógico ou ilógico, não podemos evitar".(HM,1958, p.116) Eis aqui o primeiro argumento de Hume: é inevitável apoiar-nos em algum princípio, mas não temos como justificar a escolha de um determinado princípio de modo independente de nossas crenças. Descartes, embora admitindo a inevitabilidade de um princípio, acredita num antídoto para proteger tal evidência da contaminação pela crença. $\mathrm{Na}$ verdade, o que de fato os opõe é que Peirce e Hume sustentam, contra Descartes, uma outra concepção de racionalidade. O questionamento esboçado por Hume e retomado por Peirce vai além da noção de evidência, sendo melhor expresso na pergunta: em que circunstâncias consideramos algo evidente à razão? O que equivale a abdicar da razão enquanto instância superior às condições de seu exercício, ainda que orgânicas ou psicológicas.

\begin{abstract}
"Não podemos começar pela dúvida completa. Devemos começar com todos os preconceitos que de fato temos quando começamos o estudo da filosofia. Tais preconceitos não podem ser descartados por uma máxima, pois são coisas que não nos parecem que possam ser questionadas. Assim esse ceticismo inicial será mero auto-engano, e não dúvida real; e ninguém que siga o método cartesiano se dará por satisfeito até que tenha recuperado formalmente todas aquelas crenças que abandonou formalmente." (SC,1958, p.40)
\end{abstract}

Essa via da inclinação natural é rejeitada por Descartes. Ele reconhece que a crença é uma inclinação natural forte, à qual torna-se difícil resistir. Já ao final da Meditação Primeira ele enfatizara essa idéia. Depois de passar em revista nossas diversas classes de certezas, submetendo-as aos passos demolidores da dúvida hiperbólica, Descartes declara sob suspeita tudo o que antes nos aparecia como conhecimento, certeza ou evidência. Seria desesperador, não fora o último parágrafo da Meditação. Findo o trabalho da dúvida, Descartes descansa provisoriamente. E aí lembra que é preciso vigiar para não cair em tentação. Porque a dúvida é um exercício intelectual, um método. Assim que interrompemos essa atividade, já a natureza se impõe: a lassidão, o abandono às inclinações nos leva a crer, aceitar e admitir tudo o que até aí com grande esforço pusemos sob suspeita. Sem a vigilância da razão, a natureza 
invade nosso espírito de crenças. E embora Descartes recomende sustentar o estado de dúvida até que novas certezas possam ser estabelecidas, também reconhece que a inclinação natural que nos faz crer é mais confortável. A dúvida é inquietude e disciplina; a crença conforto, serenidade e abandono à natureza.

Apenas, Descartes não confia em tal indicador. Se o que buscamos é a verdade, as inclinações naturais não são guias infalíveis. Basta pensar no pecado: trata-se de um erro; no entanto, nossas inclinações nos levam freqüentemente a preferi-lo à prática do bem. Se agir com virtude exige esforço e disciplina, assim também a busca da verdade. Contrariar uma inclinação, assim como recusar uma crença natural, não leva necessariamente ao erro; pode, ao contrário, ser o início do caminho da verdade.(Meditação Terceira, §§ 16,17).

Tais argumentos mostram que a divergência com Hume e Peirce centra-se no estatuto cognitivo da crença. Sabemos o papel central que ela desempenha na teoria humeana da causalidade. Hume recusa que possamos chegar ao conhecimento da relação de causalidade por meio de raciocínios a priori; também não temos experiência da relação causal enquanto conexão entre os fenômenos, mas apenas a da conjunção costumeira de alguns fenômenos que gera em nós a expectativa de que ela se repetirá — dado um fenômeno, esperamos que seja seguido de seu acompanhante habitual, isto é, confiamos que essa conjunção ocorra no futuro tal como no passado. Essa expectativa depende do Hábito enquanto disposição de nossa natureza, um a priori do entendimento que permite a formação de crenças causas.

\footnotetext{
"Sempre que um objeto qualquer é apresentado à memória ou aos sentidos, leva imediatamente a imaginação, pela força do costume, a conceber o objeto que habitualmente o acompanha; e essa concepção e acompanhada de um sentimento ou sensação diferente dos livres devaneios da fantasia. É nisso que consiste toda a natureza da crença”. (EHU,V,ii,§39)
}

Hume considera que atribuir princípios à natureza, como o Hábito ou capacidade de formar crenças causais, é buscar um fundamento mais seguro do que a falibilidade de nossa razão. A mesma teoria da crença reaparece na questão da percepção dos objetos físicos, para afastar o ceticismo quanto ao mundo exterior. Aparentemente, Hume começa por conceder aos céticos extremados o essencial: não há prova do mundo exterior. Porém acrescenta: nem é necessário que haja. "Podemos bem perguntar, que causas nos levam a crer na existência de corpos? Mas é vão perguntar Há ou não corpos? Este é um ponto que devemos tomar como dado em todos os nossos raciocínios." (T, p.187) E dessa crença comum também o cético compartilha. Hume transfere ao cético o 
ônus da prova. Se a crença no mundo exterior é uma fé perceptiva sem exceção, não necessita de prova. Seria preciso que o cético pudesse apresentar sua descrença de modo honesto, o que é impossível. Por isso Hume julga de maior interesse a investigação acerca da origem de tal crença em nossa mente.

$\mathrm{Na}$ teoria do conhecimento de Hume, instintos naturais, enquanto princípios da natureza humana, atuam como condições de possibilidade da percepção e do conhecimento, como o aparato cognitivo que enforma os modos de conhecer. A eles, enquanto pontos de partida ou condições de possibilidade, verdade e falsidade, erro e acerto não se aplicam. Acerca do solo de nossas percepções, como acerca de questões de fato e de existência, a razão é segunda em relação à natureza. E só no mundo dos objetos organizado pela crença ela pode atuar, agora sim metodizando e corrigindo constantemente nossas inferências, mas não o mecanismo natural de fazê-las.

Peirce também enfatiza o papel da crença na cognição:

"A dúvida é um estado de inquietação e insatisfação do qual lutamos para livrar-nos e passar ao estado de crença; enquanto que esta é um estado calmo e satisfatório que não desejamos evitar, ou mudar para uma crença em algo outro. Ao contrário, agarramo-nos tenazmente, não apenas à crença, mas a crer exatamente no que cremos".(FB,1958 p.99).

Como Hume, Peirce parece descrever um modo de operar cognitivo: passamos da crença à dúvida e a uma nova crença, como um processo regular, em todos os casos que Peirce denomina investigação. As questões de verdade e falsidade são decididas a partir do processo, contando com ele. É uma questão de método, e para Peirce, o mais eficaz deles é o método científico. Hume concordaria. Sempre que no discurso humeano ocorre uma crítica a algum raciocínio abstruso, ocorre também uma proposta formulada segundo a ciência da natureza humana que é seu intento instaurar. A expressão "proposta" é adequada: não se trata de dogmatizar, como no racionalismo fundacionista, mas de oferecer as melhores hipóteses para os fenômenos a serem explicados.

A dúvida cartesiana é recusada por Peirce e Hume porque é teórica, e, portanto pode ser estendida àqueles princípios naturais que constituem o solo de toda cognição. Ora, destes não se pode duvidar de modo sério ou mesmo sincero. Hume a considera impossível de atingir por qualquer criatura humana. Peirce recomendaria: "não encenemos duvidar em filosofia daquilo de que não duvidamos em nossos corações".(SC,1958,p.40) 


\section{Bibliografia}

COTTINGHAM, J. Dicionário Descartes. Rio de Janeiro: Zahar, 1995.

DESCARTES, R. Meditações. Objeções e Respostas. In: Obra Escolhida. São Paulo: Difusão Européia do Livro, 1960.

EMPIRICUS, S. Outlines of Pyrrhonism.Cambridge: Harvard University Press, 1976. HUME, D. An Enquiry concerning Human Understanding. L.A.Selby-Bigge; P.H.Nidditch eds. Oxford: Oxford University Press, 1988.

A Treatise of Human Nature. L.A.Selby-Bigge; P.H.Nidditch eds. Oxford:

Oxford University Press, 1989.

PEIRCE, C.S. How to Make our Ideas Clear (HM). The Fixation of Belief (FB). Some

Consequences of Four Incapacities (SC). In: Selected Writings Philip Wiener ed. New York: Dover, 1958 . 